East African Medical Journal Vol. 77 No. 5 May 2000

RECTAL DIHYDROARTEMISININ VERSUS INTRAVENOUS QUININE IN THE TREATMENT OF SEVERE MALARIA: A RANDOMISED CLINICAL TRIAL F. Esamai, MBChB, C.T.M., M.Med. (Paed), M.P.H., Associate Professor, Department of Child Health and Paediatrics, P. Ayuo, MBChB, M.Med. Lecturer, Department of Medicine, W. Owino-Ongor, MBChB., M.Med., C.T.M., MPH, Lecturer, Department of Medicine, J. Rotich, MSc. PhD, Senior Lecturer, Department of Epidemiology and Preventive Medicine, A. Ngindu, MBChB., MSc., Senior Lecturer, Department of Microbiology and Parasitology, A. Obala., HND, MSc., Chief Technician, Department of Microbiology and Parasitology, Moi University, P.O. Box 4606, Eldoret, Kenya, F. Ogaro., MBChB, M.Med. (Paed), C.T.M., Consultant Paediatrician, Moi Teaching and Referral Hospital, P.O. Box 3, Eldoret, Kenya, Li Quoqiao, Director, Vice Mayor, Guo Xingbo, Director, and Li Guangqian, Tropical Medicine Institute, Guangzhou University of Traditional Chinese Medicine, P.R. China.

Request for reprints to: Professor F. Esamai, Department of Child, Health and Paediatrics, Faculty of Health Sciences, Moi University, P.O. Box 4606, Eldoret, Kenya.

\title{
RECTAL DIHYDROARTEMISININ VERSUS INTRAVENOUS QUININE IN THE TREATMENT OF SEVERE MALARIA: A RANDOMISED CLINICAL TRIAL
}

\author{
F. ESAMAI, P. AYUO, W. OWINO-ONGOR, J. ROTICH, A. NGINDU, A. OBALA, F. OGARO, LI QUOQIAO, \\ GUO XINGBO and LI GUANGQIAN
}

\begin{abstract}
Objective: To compare the clinical efficacy and safety of rectal dihydroartemisinin (DATM - Cotecxin) and intravenous quinine in the treatment of severe malaria in children and adults. Setting: Moi Teaching and Referral Hospital, Eldoret, Kenya between July and November 1998.

Patients: A total of sixty seven patients aged two to sixty years with severe malaria were studied.

Design: This was an open randomised comparative clinical trial.

Outcome measures: These were parasite clearance time, fever clearance time, efficacy and the side effect profile of the two drugs.

Results: The two groups were comparable on admission on the clinical and laboratory parameters. The parasite clearance time was shorter in the rectal DATM group than quinine group. There was no statistical difference on the fever clearance time and cure rates in the two groups. The adverse reaction profile was better with rectal DATM than with quinine, tinnitus observed more in the quinine group.

Conclusion: Rectal DATM is faster in parasite clearance than quinine and is a safe and convenient alternative to quinine in the treatment of severe malaria.
\end{abstract}

\section{INTRODUCTION}

There are an estimated 300 - 500 million clinical cases in sub-Saharan Africa with between 1.5 - 3 million deaths of which one million are due to cerebral malaria(1-3). Commonly used drugs in the treatment of malaria in Kenya include the 4-aminoquinolones (chloroquine, amodiaquine); pyrimethamine - sulphonamide combinations and quinine. Newer additions include mefloquine, halofantrine and derivatives of artemisinin(4).

Over the last few years, multi-drug resistant strains have developed rapidly against established antimalarial drugs. Falciparum malaria resistance to most of these commonly used drugs has been demonstrated widely except artemisinin derivatives(4,7-9). This multi-drug resistance is a matter of great concern, especially in areas where high risk of malaria infection and morbidity are coupled with weak economies(9).

Artemisinin is a sesquiterpene lactone peroxide derivative of qinghaosu identified by Chinese scientists in 1985(5). These compounds are thought to be effective against multiple drug resistant $P$. falciparum malaria (uncomplicated and complicated)(5,6). Furthermore artemisinin and its derivatives act on the early ring stage parasites and may therefore prevent sequestration in the brain unlike quinine and other antimalarials which act on the mature stages of the parasites when sequestration of the parasitised erythrocytes in the brain is believed to have occurred(7).

Artemisinin is marketed in various preparations but artemisinin suppository was developed and approved for use in the treatment of falciparum malaria in China in 1985. Clinical trials so far carried out indicate that artemisinin derivatives including rectal dihydroartemisinin (DATM) have faster parasite clearance rates than intravenous quinine $(5-7,10-12)$.

Rectal DATM therefore could be a more convenient, cheap and effective alternative to the currently used antimalarials. The increasing rate of multidrug resistance of $P$. falciparum, high costs of drugs and, related equipment necessary for their administration (intravenous lines; fluids for quinine) necessitate the need for cheap, convenient and effective antimalarials.

Rectal DATM is a new drug with a new mode of administration which would meet the above requirements $(6,13)$. This study was therefore conducted with the aim of establishing the efficacy and safety of DATM in comparison to quinine in the treatment of severe $P$. falciparum malaria. 


\section{MATERIALS AND METHODS}

Patients: Consecutive patients aged 2 - 60 years from Uasin Gishu District, Kenya admitted to Moi Teaching and Referral Hospital (MTRH) with malaria positive blood slides and fulfilling the WHO criteria for severe malaria(14) were recruited into the study.

Inclusion criteria (as severe malaria) were: (i) patients with cerebral malaria with Glasgow Coma Scale of 8 or less; (ii) patients with severe anaemia with haemoglobin levels of less than $5 \mathrm{gm} / \mathrm{dl}$.; (iii) patients with hyperparasitaemia (parasite counts of more than 100,000/ul); (iv) patients with hyperpyrexia (temperature on admission of $\geq 41^{\circ} \mathrm{C}$ ); (v) patients with profuse vomiting (gastrointestinal symptoms); (vi) patients with evidence of haemolysis or black water fever; (vii) patients in shock (algid malaria) and; (viii) patients with a combination of any of the above on admission.

Exclusion criteria were: (i) patients who had been on any antimalarial in the last 72 hours before admission and; (ii) pregnancy.

Patients with severe diarrhoea were excluded in both groups due to the rectal route of administration of Cotecxin in the study group. Informed and written consent was obtained from all patients or their guardians before inclusion into the study.

Blinding: This was an open randomised comparative clinical trial.

Randomisation: A computer was used to generate numbers for randomisation into the Cotecxin and Quinine treatment groups. Those code listed 'A' got Cotecxin and 'B' got Quinine. The list was from 1 to 200 with ' $\mathrm{A}$ ' or ' $\mathrm{B}$ ' randomly assigned to each of these numbers. The patients were then assigned to either Cotecxin or Quinine on consecutive basis using this list starting from serial 1.

Antimalarial regimen: The duration of therapy in both groups was seven days and patients in either group were changed to oral medication for the last four days if they were able to take oral medication.

DATM: Dihydroartemisinin suppositories (Cotecxin suppository-Beijing COTEC New Technologies Corp. P.R. China) were administered rectally in the dose outlined below according to age. In children above eight years and adults, tablets were administered from 72 hours to day six. For those less than eight years, DATM paediatric powder at the same dosage as for suppositories was used.

Regimen of DATM suppository/tablet/powder

\begin{tabular}{|c|c|c|c|c|c|c|c|c|}
\hline \multirow{2}{*}{$\begin{array}{l}\text { Age } \\
\text { (years) }\end{array}$} & \multicolumn{7}{|c|}{ Daily doses (mg) } & \multirow{2}{*}{$\begin{array}{l}\text { Total } \\
(\mathrm{mb})\end{array}$} \\
\hline & D0 & D1 & D2 & D3 & D4 & D5 & D6 & \\
\hline$\geq 16$ & 160 & 80 & 80 & 80 & 80 & 80 & 80 & 640 \\
\hline $11-15$ & 120 & 60 & 60 & 60 & 60 & 60 & 60 & 48 \\
\hline $7-10$ & 80 & 40 & 40 & 40 & 40 & 40 & 40 & 32 \\
\hline $3-6$ & 60 & 30 & 30 & 30 & 30 & 30 & 30 & 240 \\
\hline 2 & 40 & 20 & 20 & 20 & 20 & 20 & 20 & 160 \\
\hline
\end{tabular}

Quinine: Quinine dihydrochloride (Dawa Pharmaceuticals, Kenya) was given intravenously in a dose of $20 \mathrm{mg} / \mathrm{kg}$ body weight loading dose for the first 8 hours then $10 \mathrm{mg} / \mathrm{kg}$ given 8 hourly in $10 \%$ dextrose drip until they were able to take orally. In children under eight years and those who for any reason could not take oral quinine from 72 hours intra-muscular quinine was administered upto six days.
Supportive management: Intravenous fluids (other than $10 \%$ dextrose for quinine), electrolytes and $50 \%$ dextrose were administered according to each patients requirements as assessed by the study physicians and according to laboratory reports. Antipyretics were administered as necessary when the temperature was $\geq 38.5^{\circ} \mathrm{C}$. Complications such as convulsions, acidosis, heart failure, respiratory failure or acute renal failure were dealt with using conventional modes of therapy used at the hospital.

Clinical methods:Baseline observations and investigations were done on admission and the relevant data entered in the prescribed data sheets.

All study patients were hospitalised for a minimum of seven days and discharged after review by a study physician on day six.

Temperature, pulse rate and respiratory rate were observed 6 hourly and blood pressure twice daily until discharge.

Side effects were looked for and recorded in a prescribed form every morning and evening.

Laboratory tests: Parasitology: Potential study patients were screened to confirm the adequacy of $P$. falciparum malaria parasites for inclusion into the study. Peripheral thin and thick blood smears were prepared from patients' finger prick. These were allowed to dry and thin films were fixed in absolute alcohol (methanol) after which both films were stained in $10 \%$ Giemsa stain diluted in buffered water $\mathrm{pH} 7.1$ - 7.2. The smears were allowed to dry after which they were examined under oil immersion objective. Thin smears were used to identify malaria species while the thick films were used for counting the parasites. Malaria parasites present were counted per 200 White Blood Cells (WBC) and these counts were converted to number of parasites per microlitre blood using the formula below:

$\frac{\text { Total WBC Count } x \text { No. of Parasites per } 200 \mathrm{WBC}}{200}=\begin{gathered}\text { No. of Parasites } / \\ \mu \mathrm{l} \mathrm{Blood}\end{gathered}$

WBC total count of $7200 / \mu \mathrm{l}$ blood was used for the calculation of the number of parasites per $\mu$ l of blood in this study in all cases as this is the average WBC count for MTRH population.

Patients who had asexual form counts of $\geq 300 / \mu \mathrm{l} / \mathrm{blood}$ of $P$. falciparum were recruited into the study pending investigations of other inclusion criteria. This was recorded as $\mathrm{O}$ hour blood smear after which subsequent five thick smear samples were taken at an interval of 8 hours up to 48 hours followed by two thick smears taken daily at 12 hour intervals up to Day 4 and thereafter once daily in the morning of Day 5 and Day 6. $P$. falciparum gametocytes (PFG) present were also counted and reported per $200 \mathrm{WBCs}$ in all the smears done. The smears were regarded negative when no gametocytes or any of the asexual forms were found in 200 fields in three consecutive smears. Candidate patients' blood was taken in anticoagulated and plain vacutainers for haematological and biochemical analyses respectively.

Haematological investigations: Anticoagulated blood from each patient was taken on Day 0 and Day 6, and processed for estimation of haematological indices. Each blood sample was drawn into Coulter Counter (CC) and appropriate dilutions done automatically after which different indices were estimated using inbuilt techniques in the $\mathrm{CC}$ machine. The estimated haematological indices were read off the $\mathrm{CC}$ print-out. The indices estimated were White Blood Cells (WBC $\left.\left[10^{3} / \mu 1\right]\right)$, Red

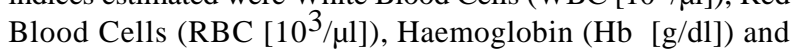
Haematocrit (HCT [\%]). Peripheral thin blood films were made using anticoagulated blood for each study patient on Day 0 and Day 6. These were stained using Giemsa stain and examined for polymorph differential counts under oil immersion objective. 
The thin smears were also used to report on the morphology, shape and size of the Red Blood Cells (RBCs). Any abnormalities detected on platelets were also reported.

Biochemistry tests: Sera were separated from the clotted blood samples after which these were used for the estimations of various biochemical parameters. The standard biochemical methods for the serum transaminases (ALT and AST) creatinine and bilirubin were used. The biochemical tests were done on Day $\mathrm{O}$ and Day 6 . The results obtained were recorded in the patients' individual files.

Urinalysis: Freshly voided urine samples were collected from each study patient on Day O and Day 6. Urinalysis tests were done on the samples using the urine dipstick model(17). The parameters determined were Specific Gravity (SG), $\mathrm{pH}$, protein, glucose, bilirubin and urobilinogen, ketones, blood and WBC.

Evaluation of efficacy and side effects: Parasite clearance times in each case was calculated and mean values between two groups were compared. Fever clearance time (FCT) was calculated for each case and the mean fever clearance time between the two groups were compared. Fever was considered to have subsided if the temperature remained below $37.5^{\circ} \mathrm{C}$ for at least 24 hours and thereafter. Side effects of the two groups were analysed and a comparison made.

Data analysis: Data was entered into the computer and the Microsoft excel statistical programme was used for data analysis.

\section{RESULTS}

The patients in the two groups were comparable in clinical and laboratory parameters as shown in Table 1 . There were no statistical significant differences between the two groups. The overall male to female ratio was 1:1.4 (quinine $=1: 1.6 ;$ cotexcin=1: 1.1). The distribution of the patients clinical signs and symptoms were comparable on admission between the two groups (Tables 2 and 3 ). The end points except for parasite clearance were comparable between the two groups (Table 4).

Table 1

Patient clinical and laboratory characteristics on admission

\begin{tabular}{|c|c|c|c|c|c|c|c|}
\hline \multirow[t]{2}{*}{ Characteristic } & \multicolumn{3}{|c|}{ Quinine $(\mathrm{n}=37)$} & \multicolumn{2}{|c|}{ Cotecxin $(n=30)$} & \multicolumn{2}{|c|}{$\mathrm{t}$-test-p $=0.05$} \\
\hline & Mean & Range & $\mathrm{Cl}$ & Mean & Range & $\mathrm{Cl}$ & 2-tail \\
\hline Age (yrs) & $14.9 \pm 3.9$ & $2.5-42$ & $11-18.8$ & $13.1 \pm 4.8$ & $2.5-50$ & $8.4-17.9$ & 0.58 \\
\hline \multicolumn{8}{|l|}{ Duration of } \\
\hline illness (days) & $3.2 \pm 0.7$ & $1-7$ & $2.5-3.9$ & $4.1 \pm 1.0$ & $1-14$ & $3.1-5.1$ & 0.15 \\
\hline \multicolumn{8}{|l|}{ Malaria episodes } \\
\hline in last six months & $0.5 \pm 0.3$ & $0-4$ & $0.2-0.9$ & $0.9 \pm 0.4$ & $0-4$ & $0.5-1.3$ & 0.2 \\
\hline \multicolumn{8}{|l|}{ Length of stay in } \\
\hline Eldoret (yrs) & $11.3 \pm 2.5$ & $2.5-30$ & $8.8-13.8$ & $9.0 \pm 3.1$ & $3-38$ & $5.9-12$ & 0.35 \\
\hline Duration of fever (days) & $3.2 \pm 0.7$ & $1-7$ & $2.5-3.8$ & $3.7 \pm 1.0$ & $1-14$ & $2.7-4.7$ & 0.43 \\
\hline Temperature $\left({ }^{\circ} \mathrm{C}\right)$ & $38.4 \pm 0.3$ & $36.2-41.0$ & $38.1-38.7$ & $38.3 \pm 0.3$ & $36.5-40$ & $38.0-38.6$ & 0.96 \\
\hline Pulse rate/min & $109 \pm 7$ & $80-140$ & $102-116$ & $111 \pm 7$ & $80-140$ & $104-118$ & 0.87 \\
\hline \multicolumn{8}{|l|}{ Respiratory } \\
\hline rate/min & $29 \pm 2$ & $20-44$ & $27-31$ & $28 \pm 3$ & $18-40$ & $25-31$ & 0.49 \\
\hline Weight (kg) & $21.8 \pm 5.2$ & $9-78$ & $16.6-27$ & $16.5 \pm 1.9$ & $10-38$ & $14.6-18.4$ & 0.23 \\
\hline Parasite count /Ê1/ & $49472 \pm 29130$ & $300-304950$ & $20342-78602$ & $29448 \pm 11877$ & $300-130400$ & $17571-41325$ & 0.16 \\
\hline Gametocyte count /Ê1/ & $222 \pm 10$ & $13-678$ & $121-323$ & $196 \pm 107$ & $71-640$ & $89-303$ & 0.91 \\
\hline $\begin{array}{l}\text { Red blood cell } \\
\text { count }\left(\times 10^{9} /\right)\end{array}$ & $3.9 \pm 0.3$ & $1.63-5.36$ & $3.6-4.1$ & $3.97 \pm 0.37$ & $1.9-6.7$ & $3.6-4.3$ & 0.78 \\
\hline Haematocrit (\%) & $33.2 \pm 2.4$ & $16.4-48.8$ & $30.8-35.6$ & $32.7 \pm 2.8$ & $18.8-49.4$ & $29.9-35.5$ & 0.79 \\
\hline \multicolumn{8}{|l|}{ White blood cell } \\
\hline count/cumm & $7984 \pm 1656$ & $2200-22600$ & $6328-9640$ & $8328 \pm 1271$ & 2300-19600 & $7057-9599$ & 0.75 \\
\hline Haemoglobin (g/dl) & $10.5 \pm 1.0$ & $3.9-17.4$ & $9.5-11.5$ & $10.2 \pm 1.1$ & $5.1-16.8$ & $9.1-11.3$ & 0.76 \\
\hline $\begin{array}{l}\text { Alanine aminotransferase } \\
\mathrm{i} \hat{\mathrm{E}} / \mathrm{I}\end{array}$ & $14.4 \pm 4.4$ & $3.5-62.5$ & $9.7-18.5$ & $11.2 \pm 2.2$ & $2.5-28.8$ & $9.0-13.4$ & 0.27 \\
\hline \multicolumn{8}{|l|}{ Aspartate } \\
\hline aminotransferase iu/l & $23.2 \pm 10.6$ & $5.2-185.1$ & $12.6-33.8$ & $19.1 \pm 5.8$ & $3.5-224.9$ & $13.3-24.9$ & 0.52 \\
\hline \multicolumn{8}{|l|}{ Serum bilirubin } \\
\hline$(\hat{\mathrm{Emol}} / \mathrm{l})$ & $13.1 \pm 4.3$ & $2-56.5$ & $8.8-17.6$ & $19.5 \pm 10.0$ & $2-131.9$ & $9.5-29.5$ & 0.26 \\
\hline \multicolumn{8}{|l|}{ Serum creatinine } \\
\hline$(\mathrm{mmol} / \mathrm{l})$ & $95.8 \pm 13.3$ & $28.5-229.8$ & $82.5-1009.1$ & $79.5 \pm 13.4$ & $12.7-175.8$ & $66.1-92.9$ & 0.12 \\
\hline
\end{tabular}


Table 2

Symptoms and signs on admission

\begin{tabular}{lccr}
\hline Symptom/finding & $\begin{array}{c}\text { Quinine } \\
(\mathrm{n}=37) \%\end{array}$ & $\begin{array}{c}\text { Cotecxin } \\
(\mathrm{n}=30) \%\end{array}$ & $\begin{array}{r}\mathrm{t} \text {-test } \\
(\mathrm{p}=0.05)\end{array}$ \\
\hline Sweating & 38 & 53 & 0.97 \\
Confusion & 26 & 23 & 0.46 \\
Headache & 84 & 83 & 0.78 \\
Chills & 73 & 86 & 0.2 \\
Vomiting & 59 & 52 & 0.58 \\
Diarrhoea & 24 & 21 & 0.79 \\
Abdominal pain & 59 & 41 & 0.22 \\
Cough & 42 & 45 & 0.85 \\
Jaundice & 3 & 7 & 0.72 \\
Bleeding & 3 & 0 & 0.98 \\
Palpable spleen & 12 & 24 & 0.54 \\
Palpable liver & 3 & 3 & 0.87 \\
\hline
\end{tabular}

Urinalysis on admission was comparable in both groups for protein, $\mathrm{pH}$, specific gravity, ketones, sugar and cytology. There was no difference in prior use of antimalarials between the two groups. Antimalarial use prior to admission was the same in the two groups.
Table 3

\begin{tabular}{|c|c|c|}
\hline Severe malaria type & Quinine $(\mathrm{n}=37)$ & Cotecxin $(n=30)$ \\
\hline Cerebral malaria & 4 & 6 \\
\hline Severe anaemia & 3 & 4 \\
\hline Hyperparasitaemia & 8 & 8 \\
\hline Hyperpyrexia & 1 & 1 \\
\hline Severe vomiting & 8 & 6 \\
\hline Algid malaria (shock) & 0 & 0 \\
\hline Black water fever & 0 & 0 \\
\hline \multicolumn{3}{|l|}{ Combination of two or } \\
\hline more of above & 13 & 5 \\
\hline
\end{tabular}

*There is no statistical difference between the groups. $\mathrm{P} \geq 0.05$

Table 4

Patients characteristics at end of the study

\begin{tabular}{|c|c|c|c|c|c|c|c|}
\hline \multirow[t]{2}{*}{ Characteristic } & \multicolumn{3}{|c|}{ Quinine $(n=37)$} & \multicolumn{3}{|c|}{ Cotecxin $(n=30)$} & \multirow{2}{*}{$\begin{array}{r}\text { t-test } \\
(\mathrm{p}=0.05) \\
\mathrm{p}\end{array}$} \\
\hline & Mean & Range & $\mathrm{Cl}$ & Mean & Range & $\mathrm{Cl}$ & \\
\hline Parasite clearance time (hrs) & $49 \pm 8.9$ & $16-90$ & $40.1-57.9$ & $38.4 \pm 6.5$ & $8-72$ & $31.9-49.9$ & 0.04 \\
\hline Gametocyte clearance time (hrs) & $9 \pm 2.1$ & $1-16$ & $6.9-11.1$ & $7.3 \pm 2.9$ & $6-16$ & 4.4-10.2 & 0.78 \\
\hline Fever clearance time (hrs) & $22 \pm 4.9$ & $0 *-60$ & $17.1-26.9$ & $27.9 \pm 8.3$ & $0 *-80$ & $19.6-36.2$ & 0.25 \\
\hline Haematocrit on discharge & $45 \pm 18.5$ & $23.7-49$ & $26.5-63.5$ & $32.1 \pm 3$ & $22.8-42.7$ & $29.1-35.1$ & 0.21 \\
\hline $\begin{array}{l}\text { Total wbc on } \\
\text { discharge/cumm }\end{array}$ & $9885 \pm 1382$ & $3800-204000$ & $8503-11267$ & $9270 \pm 1351$ & $4500-20000$ & 7919-10621 & 0.56 \\
\hline $\begin{array}{l}\text { Haemoglobin on } \\
\text { discharge }(\mathrm{g} / \mathrm{dl})\end{array}$ & $11.2 \pm 0.7$ & $6.2-16.5$ & $9.5-12.9$ & $10.1 \pm 1.0$ & $5.4-14.9$ & $9.1-11.1$ & 0.13 \\
\hline $\begin{array}{l}\text { Alanine aminotransferase on } \\
\text { discharge }(\mathrm{iu} / \mathrm{l})\end{array}$ & $9.9 \pm 2.8$ & $3.5-31.4$ & 7.1-12.7 & $26.8 \pm 1.9$ & $5.2-254.8$ & $7.8-45.8$ & 0.11 \\
\hline $\begin{array}{l}\text { Aspartate aminotransferase on } \\
\text { discharge (iu/l) }\end{array}$ & $9.9 \pm 1.8$ & $2.6-19.2$ & $8.1-11.7$ & $17.2 \pm 7.6$ & 4.4-107.4 & $9.6-24.8$ & 0.09 \\
\hline $\begin{array}{l}\text { Total bilirubin on } \\
\text { discharge (Êmol/l) }\end{array}$ & $5.0 \pm 1.5$ & $1-28.8$ & $3.5-6.5$ & $8.3 \pm 4.4$ & $2-58.5$ & $3.9-12.7$ & 0.19 \\
\hline $\begin{array}{l}\text { Creatinine on discharge } \\
(\mathrm{mmol} / \mathrm{l})\end{array}$ & $64.4 \pm 6.4$ & $18.0-123.8$ & $58-70.8$ & $66.9 \pm 7.3$ & $33-108.1$ & $59.6-74.2$ & 0.64 \\
\hline
\end{tabular}

The parasite clearance time was statistically different between the two groups. Urinalysis on discharge was comparable in both groups as was the case on admission.

$* 0$ here indicates that some patients in both groups presented without fever on admission.

Side effects: There was a higher number of cases with tinnitus in the quinine group $(n=10)$ than the Cotecxin group $(n=1)$. The other side effects were pruritus and anorexia which were observed with equal frequency in the two groups. There were no side effects in 24 and 27 cases for quinine and cotecxin groups respectively.

Efficacy: RI resistance could not be established as we did not follow our patients beyond seven days, however RII and RIII resistance were not observed in either groups. 
Figure 1a

Parasite clearance time

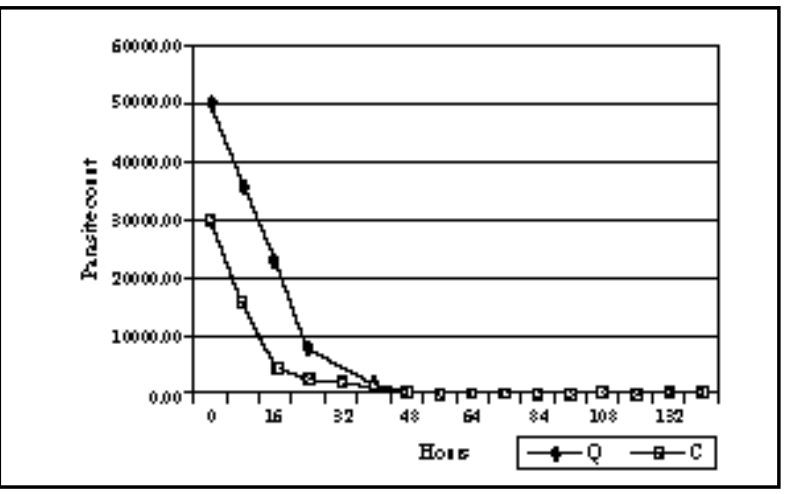

Figure 1b

Temperature clearance time

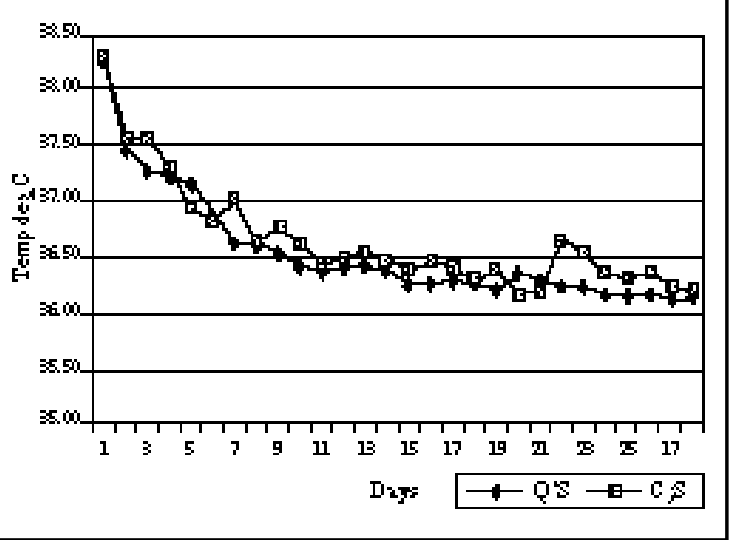

Fever and parasite clearance times: Figure 1a and $1 \mathrm{~b}$ show the parasite and fever clearance times for quinine and cotecxin. The mean parasite clearance time for quinine and cotecxin was $48 \mathrm{hrs}$ and $38.5 \mathrm{hrs}$ respectively, the difference is statistically significant $(\mathrm{p}=0.04)$. The mean fever clearance time for quinine and cotecxin was $22 \mathrm{hrs}$ and $27.5 \mathrm{hrs}$ respectively, the difference is not statistically significant $(\mathrm{p}=0.25)$. These are also shown in Table 3.

\section{DISCUSSION}

Severe malaria is a leading cause of morbidity and mortality in Kenya and other sub-Saharan African countries(1-3). This has been compounded by the fast spreading multi-drug resistance and the declining economies in these countries. These factors have neccesitated the search for cheap, effective, safe and easy to administer drugs especially for rural settings where the logistics for parenteral modes of therapy may not be practicable. Current antimalarials for severe malaria have severe side effects and are associated with logistics and supplies needed for their administration.

The use of rectal formulations of the artemisinin derivatives has been seen to be the most appropriate therapy to overcome most of these difficulties and a number of studies are under way on this front. Some studies have already been conducted with very good results using other derivatives of artemisinin (artesunate, artemether, among others) but DATM has not been tried outside China and this study could be the first using the DATM derivative suppository(10-13). These artemisinin derivatives have been found to be safe and convenient as they require only a once a day dosage(12). They have been found to be more efficacious than quinine when given in the rectal formulation as well as the parenteral route $(11,12)$. Our results show that rectal DATM has a faster parasite clearance than intravenous quinine but the fever clearance time was the same for the two drugs. These findings agree with similar studies so far conducted elsewhere using rectal formulations of artemisinin(12).

There were no deaths in this study for both groups and the cure rate was the same in the two treatment groups. No RII or RIII resistance was demonstrated as there was complete parasite clearance in all patients by 84 hours in all groups and no parasites were detected on discharge on the seventh day. RI resistance could not be established as we did not follow up our patients beyond seven days for logistic reasons. These results are similar to those reported in the literature in which rectal or parenteral artemisinin derivatives have been compared with quinine formulations in severe malaria(10-13). The results for the fever clearance time have been variable within the studies unlike for parasite clearance where universally the artemisinin derivatives have shorter times than quinine. The fever clearance time in some studies have been found to be shorter in the artemisinin than for quinine but other studies have found no statistical differences in the fever clearance time as was found in our study(12-16).

There were relatively less side effects with rectal DATM than quinine but this was not statistically significant except for tinnitus which was frequently observed among the quinine patients than among the DATM group. Renal function, liver function and haematological parameters all improved in both the quinine and cotecxin group. This agrees with findings in other studies(10-13). The cost effectiveness analysis of DATM and quinine has not been worked out in this study but would be worth looking at and determine whether DATM is cheaper than quinine when the overall cost of treatment of the patient rather than the market cost of them individually is considered. The unit cost of rectal DATM is not known in Kenya as it has not been in the market but the tablet formulation has been in the market for several years.

Cultural resentment would be expected to be one of hindrances to be encountered with use of rectal formulations of artemisinin, however, this was not found to be the case in this study as it was readily accepted. This will however, need a larger sample size for a reliable conclusion to be arrived at.

In conclusion, from the results of this study, rectal DATM is easier to administer and faster in parasite clearance than quinine and has a better adverse reactions 
profile. It would therefore be a safe, effective; easy to administer and convenient alternative to quinine in the treatment of severe malaria in both children and adults especially in peripheral health units with limited staff and supplies.

\section{ACKNOWLEDGEMENTS}

Special thanks to the Governments of Kenya and China through their respective Ministries of Health Malaria Control Programmes. Kotec (Kenya and China) are thanked for financial support. Medical Superintendent of the MTRH is thanked for permission to publish this work. Dr. Sang, J. Kirinyet, Mangeni Opo, Tanui, Biegon and Kiberenge are thanked for their support during the study. All the staff of the Paediatric and Medical wards are thanked for patient care.

\section{REFERENCES}

1. Greenword B.M., Bradley A.K., Greenwood A.M., Byass P., Jamnet K., Marsh K., Tullock S., Oldfeld F.S.S. and Hayes R. Mortality and morbidity from malaria among children in a rural area of the Gambia, West Africa. Trans. roy. Soc. trop. Med. Hyg. 1987; 81:478-486.

2. World Health Organization Statistics Quarterly 1995. Trends in Health. Vol.48, 192.

3. Menge I., Esamai F., Van Reken D. and Anabwani G.M. Paediatric morbidity and mortality at the Eldoret District Hospital, Kenya. East Afr. Med. J. 1995; 72:165-9.

4. Anabwani G.M., Esamai F.O. and Menya D.A. A randomized controlled trial to assess the relative efficacy of chloroquine, amodiaquine, halofantrine and fansidar in the treatment of uncomplicated malaria in children. East Afr. Med. J. 1996; 73:155-159.
5. Klayman D.L. Qinghaosu (artemisinin): an antimalarial drug from China. Science. 1985; 228:1049-1055.

6. Li G.Q., Guo X.B., Fu L.C., Jian H.X. and Wang X.H. Clinical trails of artemisinin and its derivatives in the treatment of malaria in China. Trans. roy. Soc. trop. Med. Hyg. 1994; 88(suppl.):5556.

7. Kokwaro, F.O. Use of artemisinin (Qinghaosu) derivatives in the treatment of malaria. Afr. J. Hlth Sci. 1998; 5:8.

8. Handerson A., Sirum J., Helia W., Navein J. and McCallum J. Polyresistant malaria in Gurka soldiers returning from Papua Guinea. Treatment and prevention. J. roy. Army Med. Corps. 1986; 132:3741

9. Division of control of tropical diseases, World Malaria situation; 1988. Wld Hlth Stat. Quart. 1990; 43: 68-79.

10. Thien T.T., Day N.P.J., Phu N.H., Mai N.T.H. and Chon T.T.H. et al. A controlled trial of artemether or quinine in Vietnamese adults with severe P. Falciparum malaria. N.Engl. J. Med. 1996; 335: $76-83$.

11. Van Hensbroek M.B., Onyiora E., Jaffar S., Schneider G. and Palmer A. A trial of artemether or quinine in children with cerebral malaria. N. Engl. J. Med. 1996; 335:69-75.

12. Birku Y., Makonnen E. and Bjorkman A. Comparison of rectal artemisinin with intravenous quinine in the treatment of severe malaria in Ethiopia. East Afr. Med. J. 1999; 76: 154-159.

13. Walker O., Salako L.A., Omokhodion S.I. and Sowunmi A. An open randomized comparative study of intramuscular artemether and intravenous quinine in cerebral malaria in children. Trans. roy. Soc. trop. Med. Hyg. 1993; 87: 564-6.

14. WHO. Practical chemotherapy of malaria. Report by WHO Scientific group. WHO Technical ser. No 1990; 805: 122-124.

15. Hien T.T., Tam D.T.H., Cuc N.J.K. and Arnlod K. Comparative effectiveness or artemisinin and oral quinine in children with acute p. falciparum malaria. Trans. roy. Soc. trop. Med. Hyg. 1991; 85: 210-211.

16. Hien T.T. and White N.J. Qinghaosu. Lancet. 1993;341: 603-608. 